\title{
Distribution of atmospheric particulate matter (PM) in rural field, rural village and urban areas of northern China
}

\author{
Wei Li ${ }^{a}$, Chen Wang ${ }^{a}$, Hongqijie Wang ${ }^{a}$, Jiwei Chen ${ }^{a}$, Chenyi Yuan ${ }^{a}$, Tongchao Li ${ }^{a}$, \\ Wentao Wang ${ }^{a}$, Huizhong Shen ${ }^{a}$, Ye Huang ${ }^{a}$, Rong Wang ${ }^{a}$, Bin Wang ${ }^{a}$, Yanyan Zhang ${ }^{a}$, \\ Han Chen ${ }^{\mathrm{a}}$, Yuanchen Chen ${ }^{\mathrm{a}}$, Jianhui Tang ${ }^{\mathrm{b}}$, Xilong Wang ${ }^{\mathrm{a}}$, Junfeng Liu ${ }^{\mathrm{a}}$, \\ Raymond M. Coveney Jr. ${ }^{\mathrm{c}}$, Shu Tao ${ }^{\mathrm{a}, *}$
}

${ }^{a}$ Laboratory for Earth Surface Processes, College of Urban and Environmental Sciences, Peking University, Beijing 100871, PR China

${ }^{\mathrm{b}}$ Yantai Institute of Coastal Zone Research, CAS, Yantai, Shandong 264003, PR China

${ }^{\mathrm{c}}$ Department of Geosciences, University of Missouri-Kansas City, Kansas City, MO 64110, USA

\section{A R T I C L E I N F O}

\section{Article history:}

Received 17 August 2013

Received in revised form

18 October 2013

Accepted 22 October 2013

\section{Keywords:}

Ambient air

$\mathrm{PM}_{10}$

Rural

China

\begin{abstract}
A B S T R A C T
Atmospheric $\mathrm{PM}_{10}$ were measured for 12 months at 18 sites along a $2500 \mathrm{~km}$ profile across northern China. Annual mean $\mathrm{PM}_{10}$ concentrations in urban, rural village, and rural field sites were $180 \pm 171$, $182 \pm 154$, and $128 \pm 89 \mu \mathrm{g} / \mathrm{m}^{3}$, respectively. The similarities in $\mathrm{PM}_{10}$ concentrations between urban and rural village sites suggest that strong localized emissions and severe contamination in rural residential areas are derived from solid fuels combustion in households. High $\mathrm{PM}_{10}$ concentrations in Wuwei and Taiyuan were caused by either sandstorms or industrial activities. Relatively low $\mathrm{PM}_{10}$ concentrations were observed in coastal areas of Dalian and Yantai. Particulate air pollution was much higher in winter and spring than in summer and fall. Multiple regression analysis indicates that $35 \%$ of the total variance can be attributed to sandstorms, precipitation and residential energy consumption. Over $40 \%$ of the measurements in both urban and rural village areas exceeded the national ambient air quality standard. (c) 2013 Elsevier Ltd. All rights reserved.
\end{abstract}

\section{Introduction}

Atmospheric particulate matter (PM) has drawn much concern because of its adverse health effects and its likely influence on global climate (Kaufman and Fraser, 1997; Pope and Dockery, 2006). Epidemiological studies point to a causal association between population exposure to fine PM in air and cardiovascular and lung cancer mortality (Pope et al., 2002; Pope and Dockery, 2006). Several mechanistic pathways of how PM may affect human health have been proposed (Brook et al., 2004).

Air pollution and particularly high concentrations of PM in air stemming from rapid industrialization, urbanization, and inadequate control strategies, social awareness, and financial investment for abatement, rank among the most critically important environmental issues in China (Vennemo et al., 2009; World Bank, 2007a). Atmospheric $\mathrm{PM}_{10}$ (PM with an aerodynamic diameter less than $10 \mu \mathrm{m}$ ) is extensively monitored in most cities, and monitoring on $\mathrm{PM}_{2.5}$ (PM with an aerodynamic diameter less than $2.5 \mu \mathrm{m}$ ) has

\footnotetext{
* Corresponding author. Tel./fax: +861062751938.

E-mail addresses: taos@urban.pku.edu.cn, taos@pku.edu.cn (S. Tao).
}

became a routine in many cities in China recently due to its close association with health effects (CNEMC; Yang et al., 2011). As noted by the World Bank (2007b), 12 of the 20 most polluted cities in the world were in China in 2004 and most of those 12 cities were located in northern China. Annual mean $\mathrm{PM}_{10}$ concentrations in one third of all routinely monitored cities in China exceed the national ambient air quality standard and most of these heavily polluted cities were also in northern China (Yang et al., 2011).

Atmospheric PM pollution results from both primary emission and secondary causes (Seinfeld and Pandis, 2006). In China, primary PM stems from a variety of anthropogenic activities including power generation, industrial processes, fossil and biomass fuel or agricultural waste combustion, and construction as well as from natural sources such as windblown dust (Sun et al., 2004; Yang et al., 2011). Secondary PM is formed by the reaction of gases or droplets of various origins in the atmosphere (Yang et al., 2011). Due to heavy dependence on coal for energy in China (NBSC, 2008), emissions of various activities are often very high. In general, air pollution is more severe in the north than that in the south because heating is required in north for several months in winter (Liu et al., 2007, 2008; Wang et al., 2011a; Zhang et al., 2009) and north China is affected by spring sandstorms much more often than the south 
(Sun et al., 2001). It is often believed that air pollution occurs mainly in cities where most power stations, industrial facilities, and motor vehicles are concentrated. However, it should be emphasized that air quality in rural China, where half population lives, is also deserving of attention even though such areas are largely not covered by routine environmental monitoring. In China, coal and biomass fuels are extensively used in rural household for cooking and heating, resulting in severe air pollution both in- and outdoors (Ding et al., 2012; Liu et al., 2007). Concentrations of polycyclic aromatic hydrocarbons (PAHs) including carcinogenic benzo[a] pyrene in the ambient environments are just about as high in northern Chinese villages as they are in major cities during the winter (Liu et al., 2007).

The objectives of this study were to investigate the $\mathrm{PM}_{10}$ concentrations along a $2500 \mathrm{~km}$ profile in northern China from Wuwei to Mou Island, east of Dalian, to compare ambient $\mathrm{PM}_{10}$ pollution between urban and rural village areas, and to characterize spatial and temporal variations of $\mathrm{PM}_{10}$ pollution. Sources, removal processes, and health effects of $\mathrm{PM}_{10}$ particles are discussed.

\section{Methodology}

2.1. Study area and PM sample collection

This study covers a broad area spanning six provinces in northern China from Gansu in the west to coastal areas in Liaoning and Shandong in the east (Fig. 1). It is generally accepted that the influence of East Asian monsoon can reach the Helan Mountains immediately north and west of Yinchuan (Zhao, 1995). The summer monsoon from the southeast carries moisture from the Pacific Ocean over mainland China in summer, creating a decreasing trend of precipitation from $\sim 630 \mathrm{~mm}$ along the coast to $\sim 110 \mathrm{~mm}$ in Wuwei, Gansu (NBSC, 2011). On the other hand, the cold and dry winter monsoon from the northwest is responsible for the sandstorms from Gobi and other deserts areas to the study area. Seven cities, namely Wuwei, Yinchuan, Taiyuan, Beijing, Dezhou, Yantai, and Dalian between $40^{\circ} \mathrm{N}$ and $37^{\circ} \mathrm{N}$ were included in this study. More information on the sampling sites are presented in Table S1 (Supplementary material). Precipitation, sandstorm frequency, and residential energy consumption data were derived from local yearbooks (NBSC, 2011), Sand-Dust Weather Almanac (CMA, 2012), and published estimates of local energy consumption in China (Zhu et al., 2013).

A total of 18 active samplers were deployed for our study among three categories of sites: seven urban (core areas of large cities), five rural village (large villages in the countryside), and six rural field ( $>500 \mathrm{~m}$ from the nearest building) (Fig. 1). $\mathrm{PM}_{10}$ samples were collected using medium volume (200$400 \mathrm{~L} / \mathrm{min}$ ) cascade impactors (PM10-PUF-300, Guangzhou, China) for $72 \mathrm{~h}$ once a month at each site during the interval between April 2010 and March 2011. Most samples (83\%) were collected simultaneously during a seven-day period in the middle of each month. $\mathrm{PM}_{10}$ samples were collected on glass fiber filters (GFFs, $200 \times 150 \mathrm{~mm}^{2}$ ), which were baked at $450{ }^{\circ} \mathrm{C}$ for $12 \mathrm{~h}$, equilibrated at $25{ }^{\circ} \mathrm{C}$ in a desiccator for $24 \mathrm{~h}$, and weighed (XS-105, Mettler Toledo, Switzerland) prior to sampling. After the sampling, GFFs were equilibrated at $25{ }^{\circ} \mathrm{C}$ in desiccator for $24 \mathrm{~h}$ and weighed again using the same balance. $\mathrm{PM}_{10}$ concentrations were calculated based on the mass differences and the total sampling volumes, which were automatically recorded by the samplers. A procedure blank (GFF through all procedures except taken out for sampling) was analyzed with each batch of samples. Mass differences of the blanks were negligible compared with the samples.

\subsection{Backward air mass trajectories and statistical analysis}

A NOAA hybrid single-particle Lagrangian integrated trajectory (HYSPLIT) model, driven by meteorological variables from global NOAA-NCEP/NCAR pressure level reanalysis data, was used to back-calculate air mass trajectories (Draxler and Rolph, 2003). Three-day backward trajectories were performed for each sampling period and the initial run times were set for six-hour intervals at 0:00, 6:00, 12:00, and 18:00 h (UTC) of each day. A potential receptor influence function was used to calculate the probability of backward trajectories of air masses reaching sampling sites (Lang et al., 2007).

Statistical analysis was performed using SPSS (IBM Statistical package for the social sciences, version 20.0). One-way analysis of variance with multiple comparisons were carried out. Pearson's method was applied for correlation analysis. A significance level of 0.05 was used for all tests.

\section{Results and discussion}

\subsection{Ambient air $P M_{10}$ concentrations}

The measured $\mathrm{PM}_{10}$ concentrations at individual sites are listed in Table 1 as means and standard deviations. The detailed monthly $\mathrm{PM}_{10}$ concentrations measured at all sites in this study are provided in Table S2 (Supplementary material). The $\mathrm{PM}_{10}$ concentrations were normally distributed with coefficients of skewness and kurtosis of $0.11(p>0.05)$ and $0.24(p>0.05)$ after log-transformation. Accordingly, the annual mean concentration of all sites is presented here as a geometric mean of $123 \mu \mathrm{g} / \mathrm{m}^{3}$ (Arithmetic means and standard deviations are estimated as $\left.163 \pm 145 \mu \mathrm{g} / \mathrm{m}^{3}\right)$.

The arithmetic means and standard deviations of ambient $\mathrm{PM}_{10}$ concentrations for the three site categories, were $128 \pm 89$, $182 \pm 154$, and $180 \pm 171 \mu \mathrm{g} / \mathrm{m}^{3}$ for rural field, rural village, and urban sites, respectively (Table 1 ). There was no significant difference between urban and rural village sites $(p>0.05)$, while the values at rural field sites were significantly lower than those of other two categories $(p<0.05)$. The relatively low concentrations were found at the rural field site at Dalian $\left(47 \pm 16 \mu \mathrm{g} / \mathrm{m}^{3}\right.$, see in Table 1), which is the sole location distant from mainland and can be regarded as a background site. The values determined for samples from all other rural field sites were relatively high because they are not too far away from cities or villages, and could well have been affected by local pollution. In general, the $\mathrm{PM}_{10}$ concentrations measured at urban sites are comparable with those reported in the literature. For instance, Wang et al. (2006) reported a range from 82 to $257 \mu \mathrm{g} / \mathrm{m}^{3}$ of $\mathrm{PM}_{10}$ concentrations in 14 northern cities in China during 2001-2002. According to Sun et al. (2004), mean $\mathrm{PM}_{10}$ concentrations in ambient air in Beijing were 164 and $255 \mu \mathrm{g} / \mathrm{m}^{3}$, in 2004 summer and winter, respectively. Among the urban and rural village sites studied, extremely high values of 1336 and $799 \mu \mathrm{g} / \mathrm{m}^{3}$

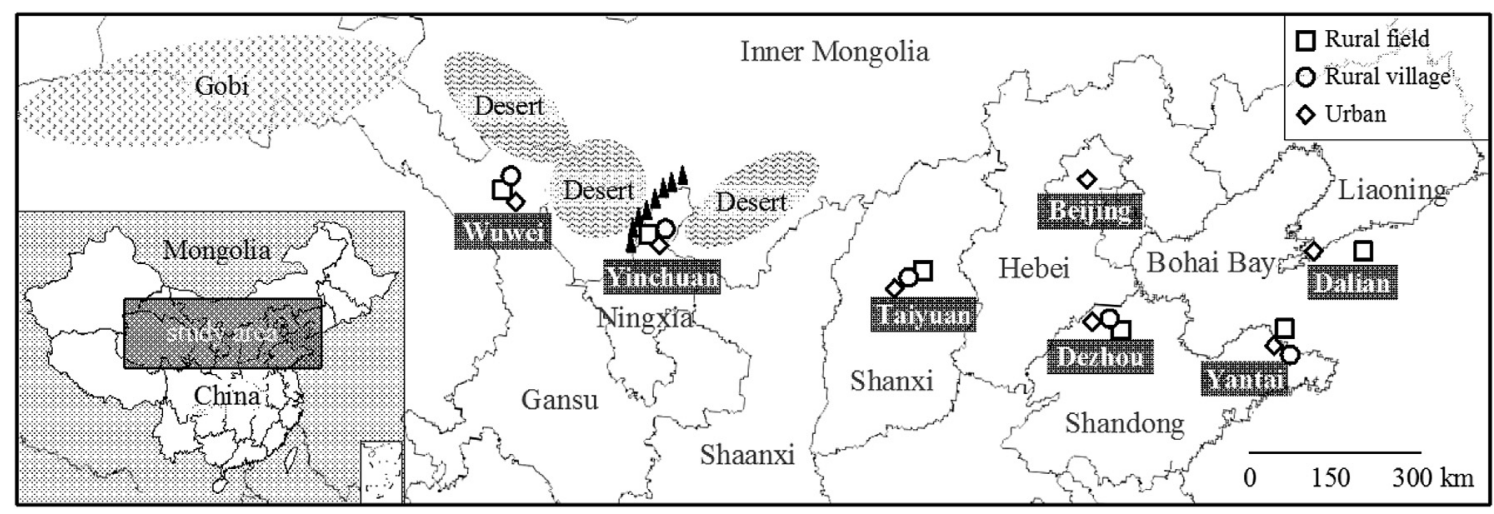

Fig. 1. Sampling locations (the triangles show the location of Helan Mountains). 
Table 1

Annual $\mathrm{PM}_{10}$ concentrations at each site as mean \pm standard deviation in $\mu \mathrm{g} / \mathrm{m}^{3}$.

\begin{tabular}{lcll}
\hline City & Rural field & Rural village & Urban \\
\hline Wuwei & $195 \pm 107$ & $354 \pm 210$ & $361 \pm 349$ \\
Yinchuan & $147 \pm 78$ & $152 \pm 89$ & $119 \pm 078$ \\
Taiyuan & $144 \pm 93$ & $182 \pm 142$ & $288 \pm 119$ \\
Beijing & & & $193 \pm 99$ \\
Dezhou & $135 \pm 39$ & $116 \pm 37$ & $140 \pm 54$ \\
Yantai & $95 \pm 99$ & $107 \pm 94$ & $103 \pm 47$ \\
Dalian & $47 \pm 16$ & & $68 \pm 29$ \\
Average & $128 \pm 89$ & $182 \pm 154$ & $180 \pm 171$ \\
\hline
\end{tabular}

were found in urban and rural village sites of Wuwei in spring, which can be explained by the influence of sandstorms (see satellite images in Fig. S1, Supplementary material).

It should be emphasized that no major differences in the measured annual mean $\mathrm{PM}_{10}$ concentrations were found between urban and rural village sites. In fact, the annual mean $\mathrm{PM}_{10}$ concentrations found at rural village sites in Yinchuan and Yantai $\left(152 \pm 89\right.$ and $\left.107 \pm 94 \mu \mathrm{g} / \mathrm{m}^{3}\right)$ were even slightly higher than those at the paired urban sites $\left(119 \pm 78\right.$ and $\left.103 \pm 47 \mu \mathrm{g} / \mathrm{m}^{3}\right)$. In the winter months, PM10 concentrations at rural village sites of Wuwei and Yinchuan were also higher than those at urban sites. A similar phenomenon has been reported by Liu et al. (2007), who conducted an extensive survey in the Northern China Plain during 2005-2006 and found that the concentrations of PAHs in ambient air in rural villages were similar to, even slightly higher than those in big cities. In a study of atmospheric PAHs in Beijing-Tianjin area, no significant difference was found between rural villages and urban sites (Wang et al., 2011b). In fact, primarily due to the previous findings, rural village and rural field sites were designed separately in this study. The rural village sites were all set up within residential areas of rural villages, while rural field sites were located in fields away from residential areas.

Rural, in contrast to urban, is a commonly used term in environmental study to refer to the areas with minimal influence of industrial and traffic pollution sources. However, rural residents in most developing countries, including China, rely heavily on coal and biomass fuel for cooking and heating (Wang et al., 2013). With simple stoves commonly used by rural residents, the amounts of many pollutants such as $\mathrm{PM}_{10}, \mathrm{SO}_{2}, \mathrm{PAHs}, \mathrm{CO}$, black carbon (BC), and organic carbon emitted from fuel combusted in rural households are several orders of magnitude higher than those for industrial facilities (Shen et al., 2010a, 2010b, 2012). As a matter of fact, it was estimated that of the 114,000 tons of PAHs emitted in China in $2004,62.6 \%$ stemmed from combustion of coal and biomass fuels in rural households in China (Zhang, 2010). Similarly, emissions of BC from the rural residential sector due to incomplete combustion of solid fuel contributed $41.4 \%$ of the total BC emission in China in 2007 (Wang et al., 2012). As a result, emissions of many pollutants, including $\mathrm{PM}_{10}$, from incomplete combustion of solid fuels in rural China (and probably in many other developing countries), account for a large fraction of total emissions, leading to severe localized ambient air pollution in rural residential areas.

\subsection{Spatial distribution}

The annual mean $\mathrm{PM}_{10}$ concentrations at all individual sites are shown in Fig. 2 in order from west to east. It appears that the measurements for the three categories of urban, rural village and rural field sites are correlated to one another significantly and the Kendall's coefficient of concordance was $0.17(p<0.05)$. This correlation suggests that $\mathrm{PM}_{10}$ concentrations strongly depend on local factors such as source strength and removal processes. The annual mean values measured at Wuwei were the highest for all three categories. Wuwei is close to the Gobi and other deserts of western China and Mongolia. Hence it is strongly influenced by sandstorms, especially in spring. In fact, the frequency of sandstorms in Wuwei is the highest of all the studied sites (CMA, 2012). Extremely high $\mathrm{PM}_{10}$ values were recorded at both urban and rural village sites there in spring. The influence of sandstorms on atmospheric PM was also demonstrated in Yinchuan with relatively weak effect due to blockage of Helan Mountains to its west (Fig. 1). On the other hand, the lowest $\mathrm{PM}_{10}$ concentrations appeared at urban and rural field sites in Dalian. The Dalian urban site was located in a coastal area on the campus of Dalian Maritime University, while the Dalian rural field site is a background site, located on an island (Mou Island) surrounded by the sea and $\sim 100 \mathrm{~km}$ to the east of Dalian.

The relatively high values in the Taiyuan area were the results of both local anthropogenic emissions and influence of spring sandstorms. As a coke and iron-steel industrial center, Taiyuan is one of the most polluted cities in China (Yang et al., 2011). Moreover, coal and coal products dominate the fuels in commercial and residential sectors in Taiyuan and the surrounding area (Meng et al., 2007). Very high concentrations of atmospheric PAHs in Taiyuan have also been reported recently (Xia et al., 2013). Beijing is represented only by a single urban site with an annual mean $\mathrm{PM}_{10}$ concentration of $193 \pm 99 \mu \mathrm{g} / \mathrm{m}^{3}$. Air pollution has long been a concern in Beijing (He et al., 2001; Jia et al., 2011; Wang et al., 2011a) and has even led to public outcry and headlines around the world during the winter of 2012-2013 (Pan et al., 2012). Still, Beijing does not rank worst

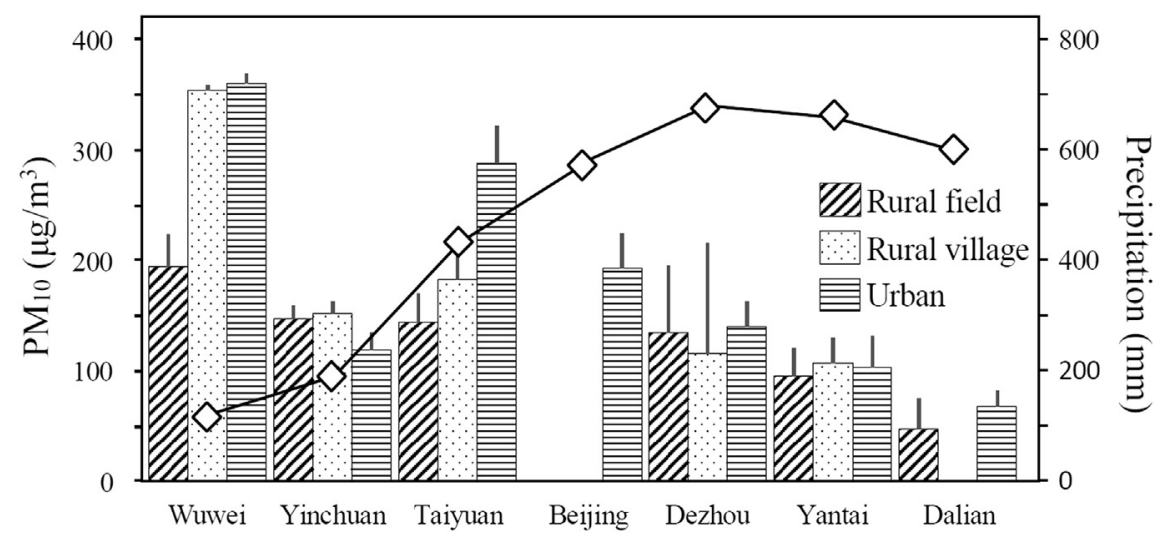

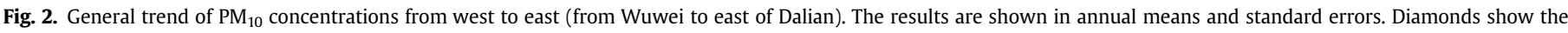
annual precipitation rates at sampling sites. 
among those areas that we studied. Unlike Taiyuan, coal burning in urban Beijing households has mostly been replaced by natural gas since 2006 (Beijing Gas), and a coke producer and a major ironsteel company have been relocated to other provinces in 2006 and 2010 (Shougang Group; Vennemo et al., 2009). Hence, the major local sources of $\mathrm{PM}_{10}$ in Beijing are likely to be aerosols associated with over three million motor vehicles on roads, coal-fired power plants, centralized heating boilers, gasoline-stations, and commercial activities (He et al., 2001; Sun et al., 2004; Yang et al., 2011). Immediately next to several other large cities and within an extremely densely populated metropolitan region, emissions from industrial, transportation, as well as household solid fuel combustion in the surrounding area also contribute to a large portion of the air pollution in Beijing (Liu et al., 2007; Wang et al., 2011a, 2011b).

$\mathrm{PM}_{10}$ pollution at a site depends on initial concentrations at the source and removal processes. Sources can be either localized or remote. Fig. 3 shows spatial distributions of probability of backward trajectories of air masses reaching the sampling sites during the sampling period. Very high probabilities adjacent to the sampling sites, shown as thick lines, suggest that most pollutants observed at these sites are either from local sources or sources in the surrounding areas. These sources can be either anthropogenic or natural (localized wind dust) (Juda-Rezler et al., 2011). For most urban sites, both primary and secondary aerosols locally generated are major sources. The air pollution is strongly affected by emissions from power generation, industry, transportation, commerce, and residences. For example, Taiyuan is a heavily industrialized city with a large number of coal-fired power generators, coke ovens, and steel furnaces (Meng et al., 2007). On the other hand, emissions from transportation and commercial activities contribute a substantial share of air pollution in Beijing (Sun et al., 2004). Dezhou, located at a transportation junction with busy motor vehicle and railway traffic, is also an industrial city and surrounded by several large coal fired power stations (Zhang, 2009). In comparison, local sources of $\mathrm{PM}_{10}$ at rural village sites are dominated by coal and biomass fuel combustion in households (Ding et al., 2012; Shen et al., 2010b). For all rural field sites, there was no appreciable local pollution source and the measured $\mathrm{PM}_{10}$ were either from nearby cities, towns, and villages or from remote areas through long-range transport.

Due to various removal processes including dry and wet deposition, only strong remote sources can significantly influence the study region. This would include sandstorms. Long-range transport of dust has been thoroughly investigated in many places in the world (Creamean et al., 2013; Juda-Rezler et al., 2011; Kim et al., 2007). For instance, it was found that atmospheric dust that originated from either the Sahara or Asia can transported across the Pacific to reach California within 10 days (Creamean et al., 2013). Due to special locations and weather, most areas in northern China are frequently impacted by sandstorms (Sun et al., 2001). As shown in Fig. 3, PM originated from the Gobi and other deserts in remote areas such as Inner-Mongolia, Xinjiang and Mongolia, did have their chances to reach the sites, with relatively low contribution though. Such long-range transport mainly occurs in winter and spring. The contributions of sandstorm to the $\mathrm{PM}_{10}$ at the sites in the west, typically Wuwei and Yinchuan, are expected to be higher than those in the east, since the major sources of sand and dust are located in west and northwest (Sun et al., 2001; Yang et al., 2011).

Wet precipitation strongly associated with local meteorological conditions is regarded as the main PM removal process (Husar et al., 2001). In contrast to the influence of sandstorms, the annual precipitation, consequently the scavenging effect, shows a decreasing trend from $633 \mathrm{~mm}$ in Dalian and Yantai in the east to $113 \mathrm{~mm}$ in Wuwei in the west (Fig. 2), primarily due to influence of East Asia Monsoon (NBSC, 2011; Zhao, 1995). Therefore, the general decreasing trend of $\mathrm{PM}_{10}$ from west to east is likely due to the declining influence of sandstorm and the increasing influence of precipitation.

\subsection{Seasonal variation in $P M_{10}$ concentrations}

Fig. 4 shows seasonality of the measured $\mathrm{PM}_{10}$ concentrations as means and standard errors of all sites for the three categories of rural field, rural village, and urban. It is interesting to see that the Kendall's coefficient of concordance among the three categories was significant $(p<0.05)$. Thus, temporal trends of the sites were concordant, although the concentrations at the majority of rural field sites were lower than those of the corresponding rural village and urban sites. $\mathrm{PM}_{10}$ concentrations were similar between urban and rural village sites. In addition, the seasonal variation patterns of $\mathrm{PM}_{10}$ concentrations at various sites from the east coastal area to west inland were also similar to one another. As previously discussed, $\mathrm{PM}_{10}$ observed at the three categories of sites were from different sources and underwent similar removal processes. Among them, emissions from anthropogenic sources, sand of eolian origin, and wet precipitation are potentially different among seasons. The correlation among the three categories of sites and the similar seasonality among locations suggest that the seasonality of $\mathrm{PM}_{10}$ concentrations under the control of a same set of factors.

Among all anthropogenic sources, residential sector emission shows strong seasonal variation. It was estimated that per-capital coal and biomass fuel consumption in the residential sector in China were 0.13 and 0.72 tons, respectively (Wang et al., 2013). For the studied sites, the average temperatures in winter were from -5.0 to $3.0^{\circ} \mathrm{C}$ and the heating degree days (the accumulated degree deviations from a base temperature during heating period, where the predefined base temperature is the temperature above which heating is needed) were from 471 to 2165 if $5^{\circ} \mathrm{C}$ was used as

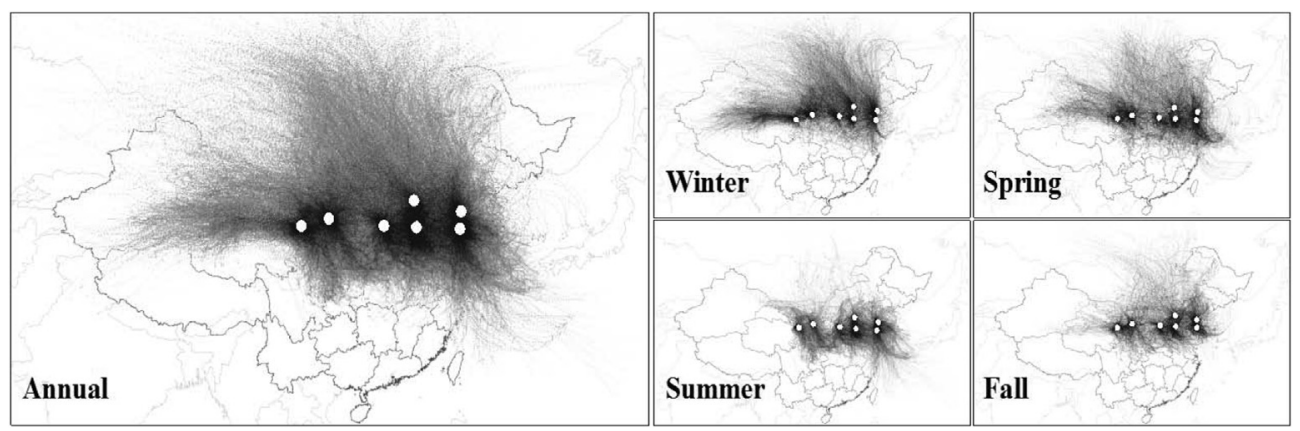

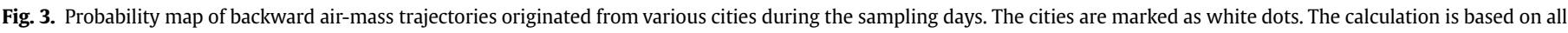
sampling days of the study period (Annual) and sampling days of individual seasons (four seasons). 


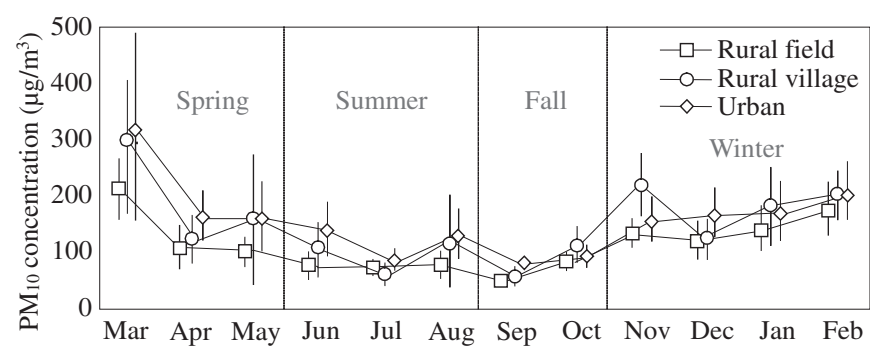

Fig. 4. Seasonal variations in $\mathrm{PM}_{10}$ concentrations at rural field, rural village, and urban sites. Arithmetic means and standard errors are shown.

base temperature (NBSC, 2011; Zhu et al., 2013). As a result, extra fuel is needed during the heating season, which usually lasts from early November to the middle of March in northern China (Wang et al., 2011b; Zhu et al., 2013). It was reported that residential fuel consumption rates in northern China during the winter were generally 1.5-2 times of those in summer (Liu et al., 2008; Qin et al., 2007). Consequently, $\mathrm{PM}_{10}$ concentrations in non-heating season are generally lower than those in heating season. It is also interesting to note that the $\mathrm{PM}_{10}$ concentrations at rural village sites were often higher than those at urban sites during the heating season when a huge amount of coal and biomass fuels was burned in rural households for heating. In comparison, the $\mathrm{PM}_{10}$ concentrations at rural village sites were generally lower than those in urban areas in non-heating season, when solid fuels were only used for cooking. Again, the influence of household fuel consumption on ambient air pollutant is well demonstrated.

For most sites included in this study, the coldest months are December and January, when both fuel consumption and pollutant emission reach their maximum each year (Liu et al., 2008; Zhu et al., 2013). However, the highest $\mathrm{PM}_{10}$ concentrations, along with the highest standard deviations, were recorded in March. Northern China is frequently hit by sandstorms in spring time when dry cold fronts often sweep over the region, bringing large quantities of dust from the Gobi and other deserts in Mongolia and Xinjiang and Inner-Mongolia, China (Sun et al., 2004). Because of this, the March peak appeared at all sites except Dalian, which was not affected by sandstorms. The potential effect of sandstorms on these sites can also be seen in Fig. 3 (spring), in which the backward trajectories of air mass reaching most sampling sites can be traced to Mongolia and Xinjiang deserts. In fact, several severe dust events were recorded in spring of 2011 (CMA, 2012) and sampling was affected at most sites except those in Dalian by these sandstorms during March (see the satellite images in Fig. S1, Supplementary material). The influence of sandstorms on atmospheric PM levels in northern China in spring has been widely reported (Sun et al., 2001; Wang et al., 2006). It has been estimated that $79 \%$ of mineral particles in $\mathrm{PM}_{10}$ that occurred in Beijing were from outside of the city during days with sandstorms (Sun et al., 2004).

Another important factor affecting the seasonality of $\mathrm{PM}_{10}$ concentration is atmospheric precipitation, which can scavenge airborne particles, by wet deposition. Under the influence of the East Asia Monsoon, the bulk of the annual precipitation at most sites occurs in summer from June to September (Fig. 5). During this period, the observed $\mathrm{PM}_{10}$ concentrations at all sites were among the lowest of the year. The scavenging effects of precipitation on atmospheric pollutants in northern China has also been demonstrated by other studies (Liu et al., 2008; Wang et al., 2011b). In summary, the seasonal variations of $\mathrm{PM}_{10}$ concentrations are mainly affected by three factors: coal and biomass fuel combustion for heating in winter, sandstorms during the spring, and summer rain events. Such influences are summarized in Fig. 5.

The influences of local emissions, sandstorms, and precipitation are quantitatively presented by calculating correlations of $\mathrm{PM}_{10}$ concentrations with residential energy consumption, sandstorm frequency, and monthly precipitation individually. The results are shown in Fig. 6 and the correlations are all significant $(p<0.05)$. Although sandstorm frequency is a discrete variable and is not normally distributed, the increasing trend of $\mathrm{PM}_{10}$ as the frequency increases is clearly shown. If the three factors are used as independent variables for a regression analysis for predicting $\mathrm{PM}_{10}$ concentration based on the data collected in this study, with precipitation and energy consumption standardized to remove scale difference among them, the following equation was derived:

$$
\text { (2) } \log P M=-0.068 P S+0.058 E s+2.171 S+2.045, R^{2}=0.355
$$

where $P M$ and $S$ are $\mathrm{PM}_{10}$ concentrations $\left(\mu \mathrm{g} / \mathrm{m}^{3}\right)$ and sandstorm frequency, $P$ s and Es represent the standardized precipitation $(\mathrm{mm})$, residential energy consumption [ton coal equivalent (tce) per capita], respectively. All regression coefficients are significant at a level below 0.05 except Es, which is significant at 0.06 . More than one third of the variance in $\mathrm{PM}_{10}$ concentrations can be attributed to three factors: atmospheric precipitation, local emissions related to residential energy consumption, and the frequency of sandstorms.

Many other factors may also affect the seasonal variations of atmospheric $\mathrm{PM}_{10}$ concentrations. Lower boundary layer height often leads to higher atmospheric PM concentrations (Koelemeijer et al., 2006), and the boundary layer height of sampling sites was higher in summer than winter (Emmons et al., 2010). Prevailing

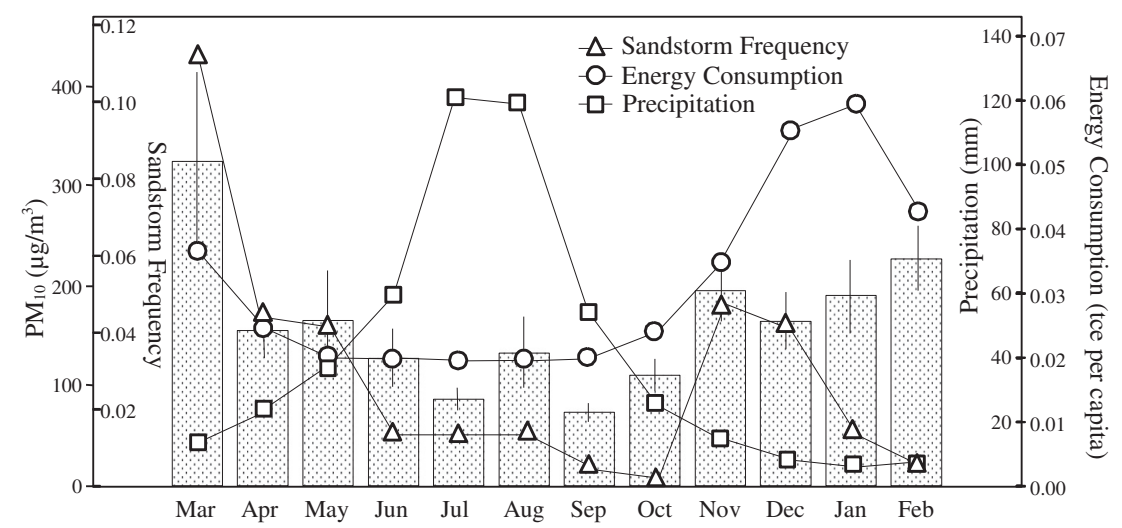

Fig. 5. Dependence of atmospheric $\mathrm{PM}_{10}$ concentrations (means and standard errors) on monthly residential energy consumption, precipitation, and sandstorm frequency. 

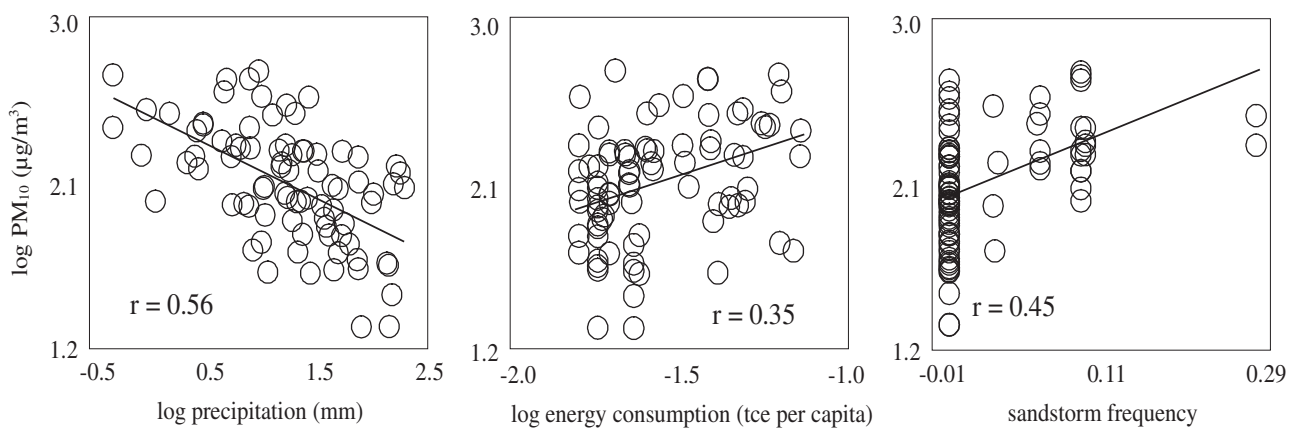

Fig. 6. Correlations between PM10 concentrations and precipitation, energy consumption (as an indicator of local emission), and sandstorm frequency (from left to right).

winds from severely contaminated regions can bring more PMs to the sampling sites. For example, wind from the south or the east of Beijing can often bring pollutants from heavily industrialized and populated Tianjin and Baoding areas, while northwest wind from the Yan Mountains can usually clear the air in the city except during spring when sandstorms tend to hit the city (Wang et al., 2011b). The frequency of development of secondary aerosols also varies with the seasons. It should be noted that studies of urban and rural areas in Europe suggest that the lowest secondary organic carbon in air occurs during the winter (Castro et al., 1999). In contrast, during the summer, secondary organic aerosol formation can be intensified at high temperatures, provided there is sufficient sunlight (Seinfeld and Pandis, 2006).

\subsection{Health effects}

Atmospheric $\mathrm{PM}_{10}$ contents are now routinely monitored by Environmental Monitoring Stations under the Ministry of Environmental Protection around the country; $\mathrm{PM}_{2.5}$ measurements were not included in some large cities until late 2012 (CNEMC). $\mathrm{PM}_{10}$ is also the only PM parameter regulated in China until 2012 and the current national ambient air quality standard (GB 30952012) for daily average $\mathrm{PM}_{10}$ concentration is $150 \mu \mathrm{g} / \mathrm{m}^{3}$ (MEP, 2012). Although this is not a strict standard in comparison with the WHO guideline $\left(50 \mu \mathrm{g} / \mathrm{m}^{3}\right)$ (WHO, 2011), of all data collected in this study, $40 \%$ of them exceeded the national standard. The rates of excess values were $\sim 42 \%$ for both urban and rural village sites. The contamination in cities has recently raised attention nationwide (World Bank, 2007a), but much less attention has been paid to rural areas, where approximately half the national population lives and where ambient air quality is often as poor as that in cities (Liu et al., 2007). Epidemiological studies have provided sound evidence that both short-term and long-term exposures to atmospheric particles can cause various health problems, particularly respiratory and cardiovascular diseases (Kaufman and Fraser, 1997; Pope and Dockery, 2006). According to the recently published results on disease burden, ambient PM pollution ranked fourth among all risk factors in China and was responsible for 1.27 million premature deaths in East Asia during 2010 (IHME, 2013). This finding is generally expectable given the high levels of $\mathrm{PM}_{10}$ in both urban and rural village sites in northern China.

It is well established that in northern China the air quality is worse inside of rural households than outside air and that the majority of residents spend more time indoors (Ding et al., 2012). Hence, the overall health risk facing rural residents should be much higher than for those living in cities. This is also supported by the fact that household air pollution ranks as the fifth leading risk factor in China (IHME, 2013; Yang et al., 2013). No doubt, China has a long road ahead in improving air quality, both within households and outdoors. While policy makers have recently turned their attention to the issue and promised more investment on pollution controls in cities, not enough concern has been raised over rural household air quality. In many cases, promotion of clean stoves and clean fuels in rural households could reduce emissions dramatically (Anenberg et al., 2013), suggesting that the cost for saving lives in rural China could be less expensive and time consuming than in cities, though action is clearly warranted in both cases (Wang, 2013).

\section{Conclusion}

Atmospheric $\mathrm{PM}_{10}$ concentrations at the rural field sites were significantly lower than those in the rural village and urban area, while no significant difference was found between the latter two. Strong local emission from coal and biomass fuel combustion for heating and cooking contributed to the high levels of $\mathrm{PM}_{10}$ in the rural villages, which should draw more attention, since about half of the population in China live in the rural area. Different spatial distribution of sources, such as sandstorm and industrial activities, and removal effects, like precipitation, caused high $\mathrm{PM}_{10}$ concentrations in Wuwei and Taiyuan and low concentrations in the coastal area. A strong seasonality with more severe $\mathrm{PM}_{10}$ contamination in spring and winter than that in summer and autumn was observed. Sandstorms, residential energy consumption, and precipitation explained $35 \%$ of the total variance in atmospheric $\mathrm{PM}_{10}$ concentrations in the study area. More than $40 \%$ of observed $\mathrm{PM}_{10}$ concentrations in both urban and rural village areas exceeded the national ambient air quality standard.

\section{Financial interest}

The authors declare no competing financial interest.

\section{Acknowledgment}

Funding for this study was provided by the National Natural Science Foundation of China (41130754; 41101490) and Beijing Municipal Government (YB20101000101).

\section{Appendix A. Supplementary data}

Supplementary data related to this article can be found at http:// dx.doi.org/10.1016/j.envpol.2013.10.042.

\section{References}

Anenberg, S.C., Balakrishnan, K., Jetter, J., Masera, O., Mehta, S., Moss, J., Ramanathan, V., 2013. Cleaner cooking solutions to achieve health, climate, and economic cobenefits. Environ. Sci. Technol. 47 (9), 3944-3952.

Beijing Gas Website, http://www.bjgas.com/news.aspx?id=2531 (accessed April 2013). 
Brook, R.D., Franklin, B., Cascio, W., Hong, Y., Howard, G., Lipsett, M., Luepker, R., Mittleman, M., Samet, J., Smith, S.C., Tager, I., 2004. Air pollution and cardiovascular disease A statement for healthcare professionals from the expert panel on population and prevention science of the American Heart Association. Circulation 109 (21), 2655-2671.

Castro, L.M., Pio, C.A., Harrison, R.M., Smith, D.J.T., 1999. Carbonaceous aerosol in urban and rural European atmospheres: estimation of secondary organic carbon concentrations. Atmos. Environ. 33 (17), 2771-2781.

China Meteorological Administration (CMA), 2012. Sand-dust Weather Almanac 2010. China Meteorological Press, Beijing.

China National Environmental Monitoring Centre (CNEMC) Website, http://www. cnemc.cn/ (accessed April 2013).

Creamean, J.M., Suski, K.J., Rosenfeld, D., Cazorla, A., DeMott, P.J., Sullivan, R.C. White, A.B., Ralph, F.M., Minnis, P., Comstock, J.M., Tomlinson, J.M., Prather, K.A., 2013. Dust and biological aerosols from the Sahara and Asia influence precipitation in the Western US. Science 339 (6127), 1572-1578.

Ding, J., Zhong, J., Yang, Y., Li, B., Shen, G., Su, Y., Wang, C., Li, W., Shen, H., Wang, B., Wang, R., Huang, Y., Zhang, Y., Cao, H., Zhun, Y., Simonich, S.L.M., Tao, S., 2012. Occurrence and exposure to polycyclic aromatic hydrocarbons and their derivatives in a rural Chinese home through biomass fuelled cooking. Environ. Pollut. 169, 160-166.

Draxler, R.R., Rolph, G.D., 2003. HYSPLIT (HYbrid Single-particle Lagrangian Integrated Trajectory) Model. NOAA Air Resources Laboratory, Silver Spring, MD.

Emmons, L.K., Walters, S., Hess, P.G., Lamarque, J.F., Pfister, G.G., Fillmore, D. Granier, C., Guenther, A., Kinnison, D., Laepple, T., Orlando, J., Tie, X., Tyndall, G., Wiedinmyer, C., Baughcum, S.L., Kloster, S., 2010. Description and evaluation of the model for ozone and related chemical tracers, version 4 (MOZART-4). Geosci. Model Dev. 3 (1), 43-67.

He, K., Yang, F., Ma, Y., Zhang, Q., Yao, X., Chan, C.K., Cadle, S., Chan, T., Mulawa, P., 2001. The characteristics of $\mathrm{PM}_{2.5}$ in Beijing, China. Atmos. Environ. 35 (29), 4959-4970.

Husar, R.B., Tratt, D.M., Schichtel, B.A., Falke, S.R., Li, F., Jaffe, D., Gassó, S., Gill, T., Laulainen, N.S., Lu, F., Reheis, M.C., Chun, Y., Westphal, D., Holben, B.N. Gueymard, C., McKendry, I., Kuring, N., Feldman, G.C., McClain, C., Frouin, R.J., Merrill, J., DuBois, D., Vignola, F., Murayama, T., Nickovi, S., Wilson, W.E., Sassen, K., Sugimoto, N., Malm, W.C., 2001. Asian dust events of April 1998. J. Geophys. Res. Atmos. (1984-2012) 106 (D16), 18317-18330.

Inst. Health Metrics \& Evaluation (IHME), 2013. Global Burden of Diseases, Injuries, and Risk Factors Study 2010. GBD Profile, China. http://www. healthmetricsandevaluation.org/gbd/country-profiles (accessed April 2013).

Jia, Y., Stone, D., Wang, W., Schrlau, J., Tao, S., Simonich, S.L.M., 2011. Estimated reduction in cancer risk due to PAH exposures if source control measures during the 2008 Beijing Olympics were sustained. Environ. Health Perspect. 119 (6), 815.

Juda-Rezler, K., Reizer, M., Oudinet, J.P., 2011. Determination and analysis of $\mathrm{PM}_{10}$ source apportionment during episodes of air pollution in Central Eastern European urban areas: the case of wintertime 2006. Atmos. Environ. 45 (36), 6557-6566.

Kaufman, Y.J., Fraser, R.S., 1997. The effect of smoke particles on clouds and climate forcing. Science 277 (5332), 1636-1639.

Kim, J., Jung, C.H., Choi, B.C., Oh, S.N., Brechtel, F.J., Yoon, S.C., Kim, S.W., 2007. Number size distribution of atmospheric aerosols during ACE-Asia dust and precipitation events. Atmos. Environ. 41 (23), 4841-4855.

Koelemeijer, R.B.A., Homan, C.D., Matthijsen, J., 2006. Comparison of spatial and temporal variations of aerosol optical thickness and particulate matter over Europe. Atmos. Environ. 40 (27), 5304-5315.

Lang, C., Tao, S., Zhang, G., Fu, J., Simonich, S., 2007. Outflow of polycyclic aromatic hydrocarbons from Guangdong, Southern China. Environ. Sci. Technol. 41 (24), 8370-8375.

Liu, S., Tao, S., Liu, W., Liu, Y., Dou, H., Zhao, J., Wang, L., Wang, J., Tian, Z., Gao, Y., 2007. Atmospheric polycyclic aromatic hydrocarbons in north China: a wintertime study. Environ. Sci. Technol. 41 (24), 8256-8261.

Liu, S., Tao, S., Liu, W., Dou, H., Liu, Y., Zhao, J., Little, M.G., Tian, Z., Wang, J., Wang, L. Gao, Y., 2008. Seasonal and spatial occurrence and distribution of atmospheric polycyclic aromatic hydrocarbons (PAHs) in rural and urban areas of the North Chinese Plain. Environ. Pollut. 156 (3), 651-656.

Meng, Z.Y., Jiang, X.M., Yan, P., Lin, W.L., Zhang, H.D., Wang, Y., 2007. Characteristics and sources of $\mathrm{PM}_{2.5}$ and carbonaceous species during winter in Taiyuan, China. Atmos. Environ. 41 (32), 6901-6908.

Ministry of Environmental Protection (MEP), 2012. Ambient Air Quality Standards (GB3095-2012). China Environmental Science Press, Beijing.

National Bureau of Statistics of China (NBSC), 2008. China Energy Statistical Yearbook 2007. China Statistics Press, Beijing.

National Bureau of Statistics of China (NBSC), 2011. Yearbook 2010 of Gansu, Ningxia, Shanxi, Beijing, Shandong, Liaoning. China Statistics Press, Beijing.

Pan, X., Li, G., Gao, T., 2012. Dangerous Breath: Research on Health Risks and Economic Loss Linked to $\mathrm{PM}_{25}$. China Environmental Science Press, Beijing.

Pope III, C.A., Burnett, R.T., Thun, M.J., Calle, E.E., Krewski, D., Ito, K., Thurston, G.D., 2002. Lung cancer, cardiopulmonary mortality, and long-term exposure to fine particulate air pollution. J. Am. Med. Assoc. 287 (9), 1132-1141.

Pope III, C.A., Dockery, D.W., 2006. Health effects of fine particulate air pollution: lines that connect. J. Air Waste Manag. Assoc. 56 (6), 709-742.
Qin, F., Liu, H.Y., Jing, L., Liu, W., Yin, J., Wei, X.D., 2007. The investigation of energy consumption in the village of Jilin Province. J. Jilin Arch. Civil Eng. Inst. 24, $37-$ 40 (in Chinese).

Seinfeld, J.H., Pandis, S.N., 2006. Atmospheric Chemistry and Physics: From Air Pollution to Climate Change, second ed. John Wiley \& Sons, Inc., U.S.

Shen, G., Wang, W., Yang, Y., Zhu, C., Min, Y., Xue, M., Ding, J., Li, W., Wang, B., Shen, H., Wang, R., Wang, X., Tao, S., 2010a. Emission factors and particulate matter size distribution of polycyclic aromatic hydrocarbons from residentia coal combustions in rural Northern China. Atmos. Environ. 44 (39), 5237-5243.

Shen, G., Yang, Y., Wang, W., Tao, S., Zhu, C., Min, Y., Xue, M., Ding, J., Wang, B. Wang, R., Shen, H., Li, W., Wang, X., Russell, A., 2010b. Emission factors of particulate matter and elemental carbon for crop residues and coals burned in typical household stoves in China. Environ. Sci. Technol. 44 (18), 7157-7162.

Shen, G., Shu, T., Wei, S., Zhang, Y., Wang, R., Wang, B., Li, W., Shen, H., Huang, Y., Chen, Y., Chen, H., Yang, Y., Wang, W., Wang, X., Liu, W., Simonich, S.L.M., 2012 Emissions of parent, nitro, and oxygenated polycyclic aromatic hydrocarbons from residential wood combustion in rural China. Environ. Sci. Technol. 46 (15), 8123-8130.

Shougang Group Website, http://www.shougang.com.cn/shougang_cn_web/gslcdy. htm (accessed April 2013).

Sun, J., Zhang, M., Liu, T., 2001. Spatial and temporal characteristics of dust storms in China and its surrounding regions, 1960-1999: Relations to source area and climate. J. Geophys. Res. 106 (D10), 10325-10410.

Sun, Y., Zhuang, G., Wang, Y., Han, L., Guo, J., Dan, M., Zhang, W., Wang, Z., Hao, Z. 2004. The air-borne particulate pollution in Beijing-concentration, composition, distribution and sources. Atmos. Environ. 38 (35), 5991-6004.

Vennemo, H., Aunan, K., Lindhjem, H., Seip, H.M., 2009. Environmental pollution in China: status and trends. Rev. Environ. Econ. Policy 3 (2), 209-230.

Wang, S., Yuan, W., Shang, K., 2006. The impacts of different kinds of dust events on $\mathrm{PM}_{10}$ pollution in northern China. Atmos. Environ. 40 (40), 7975-7982.

Wang, W., Jariyasopit, N., Shrlau, J., Jia, Y., Tao, S., Yu, T.-W., Dashwood, R.H., Zhang, W., Wang, X., Simonich, S.L.M., 2011a. Concentration and photochemistry of PAHs, NPAHs, and OPAHs and toxicity of $\mathrm{PM}_{2 .} 5$ during the Beijing Olympic Games. Environ. Sci. Technol. 45 (16), 6887-6895.

Wang, W., Simonich, S., Giri, B., Chang, Y., Zhang, Y., Jia, Y., Tao, S., Wang, R., Wang, B. Li, W., Cao, J., Lu, X., 2011b. Atmospheric concentrations and air-soil gas exchange of polycyclic aromatic hydrocarbons (PAHs) in remote, rural village and urban areas of Beijing-Tianjin region, North China. Sci. Total Environ. 409 (15), $2942-2950$.

Wang, R., Tao, S., Wang, W., Liu, J., Shen, H., Shen, G., Wang, B., Liu, X., Li, W., Huang, Y., Lu, Y., Chen, H., Chen, Y., Wang, C., Zhu, D., Wang, X., Li, B., Liu, W., Ma, J., 2012. Black carbon emissions in China from 1949 to 2050. Environ. Sci. Technol. 46 (14), 7595-7603.

Wang, Q., 2013. China's citizens must act to save their environment. Nature 497, 189.

Wang, R., Tao, S., Ciais, P., Shen, H.Z., Huang, Y., Chen, H., Shen, G.F., Wang, B., Li, W., Zhang, Y.Y., Lu, Y., Zhu, D., Chen, Y.C., Liu, X.P., Wang, W.T., Wang, X.L., Liu, W.X., Li, B.G., Piao, S.L., 2013. High-resolution mapping of combustion processes and implications for $\mathrm{CO}_{2}$ emissions. Atmos. Chem. Phys. 13, 1-15.

WHO, 2011. Air Quality and Health (Updated 2011.9). http://www.who.int/ mediacentre/factsheets/fs313/en/ (accessed April 2013).

World Bank, 2007a. Cost of Pollution in China: Economic Estimates of Physical Damages. World Bank, Washington, DC. http://documents.worldbank.org/ curated/en/2007/02/7503894/cost-pollution-china-economic-estimatesphysical-damages (accessed April 2013).

World Bank, 2007b. World Development Indicators 2007. World Bank, Washington, DC. http://siteresources.worldbank.org/DATASTATISTICS/Resources/table3_13. pdf (accessed April 2013).

Xia, Z., Duan, X., Tao, S., Qiu, W., Liu, D., Wang, X., Wei, S., Wang, B., Jiang, Q., Lu, B. Song, Y., Hu, X., 2013. Pollution level, inhalation exposure and lung cancer risk of ambient atmospheric polycyclic aromatic hydrocarbons (PAHs) in Taiyuan, China. Environ. Pollut. 173, 150-156.

Yang, F., Tan, J., Zhao, Q., Du, Z., He, K., Ma, Y., Duan, F., Chen, G., Zhao, Q., 2011 Characteristics of $\mathrm{PM}_{2.5}$ speciation in representative megacities and across China. Atmos. Chem. Phys. 11 (11), 5207-5219.

Yang, G., Wang, Y., Zeng, Y., Gao, G.F., Liang, X., Zhou, M., Wan, X., Yu, S., Jiang, Y. Naghavi, M., Vos, T., Wang, H., Lopez, A., Murray, C., 2013. Rapid health transition in China, 1990-2010: findings from the global burden of disease study 2010. Lancet 381 (9882), 1987-2015.

Zhang, Q., 2009. The Study on the Correlation Between Air Pollution and Lung Diseases in Dezhou City (Master's thesis). Shandong University, Jinan, Shandong.

Zhang, Y., Tao, S., Shen, H., Ma, J., 2009. Inhalation exposure to ambient polycyclic aromatic hydrocarbons and lung cancer risk of Chinese population. Proc. Natl. Acad. Sci. 106 (50), 21063-21067.

Zhang, Y., 2010. Polycyclic Aromatic Hydrocarbons in China: Emission, Atmospheric Transport and Lung Cancer Risk (Ph.D. dissertation). Peking University, Beijing. Zhao, J., 1995. China Natural Geography, third ed. Higher Education Press, Beijing. Zhu, D., Tao, S., Wang, R., Shen, H., Huang, Y., Shen, G., Wang, B., Li, W., Zhang, Y., Chen, H., Chen, Y., Liu, J., Li, B., Wang, X., Liu, W., 2013. Temporal and spatial trends of residential energy consumption and air pollutant emissions in China. Appl. Energy 106, 17-24. 